\title{
INTER-RELAÇÃO TRATAMENTO ORTODÔNTICO E DISFUNÇÕES TEMPOROMANDIBULARES: UMA ANÁLISE CRÍTICA DAS EVIDÊNCIAS ATUAIS
}

Eduardo MACHADO, Daniel BONOTTO, Paulo Afonso CUNALI

A inter-relação Ortodontia e Disfunção temporomandibular (DTM) tem despertado interesse crescente na classe Odontológica nos últimos anos, sendo tema de discussões e controvérsias. Em um passado recente, a oclusão era considerada como principal fator etiológico das DTM, sendo o tratamento ortodôntico uma medida terapêutica primária para um restabelecimento fisiológico do sistema estomatognático. Assim, o papel da Ortodontia na prevenção, tratamento e desencadeamento das DTM passou a ser investigado. Com a realização de estudos científicos com metodologias mais rigorosas e precisas, a relação entre o tratamento ortodôntico e as DTM pôde ser avaliada e questionada dentro de um contexto baseado em evidências científicas. Este trabalho, através de uma revisão de literatura tendo como base de pesquisa a MEDLINE, LILACS e BBO entre os anos de 1998 a 2007, com enfoque em estudos clínicos randomizados e não randomizados, estudos prospectivos, retrospectivos, longitudinais, coorte, casos-controle e metaanálises, teve como objetivo analisar a inter-relação entre o tratamento ortodôntico e as DTM, verificando se o tratamento ortodôntico é fator contribuinte para o desenvolvimento de DTM. Pela análise da literatura, conclui-se que o tratamento ortodôntico não pode ser considerado fator contribuinte para desenvolvimento de disfunções temporomandibulares. 